\title{
The Influence of Freight Trains on the Air Cargo in Kuwait International Airport
}

\author{
Fadala Hassan Alfadala
}

\begin{abstract}
Surrounded by countries who are moving continually towards economic development and stability, Kuwait has moved to establishing freight trains on the Air Cargo in Kuwait International Airport to meet the ever changing and increasing number of both passenger and cargoes going in and out of the country. As a member of the Gulf Cooperation Council or GCC it is clearly seen that as most of its member countries drive towards a collective effort to connect together by means of railroad networks, Kuwait's effort to move transportation of cargoes to and from the Kuwait International Airport by linking with the GCC's project to create railroad networks, the proposed "Cargo City" becomes a major part of the realization of the development of the KIA which shall help with the aim to widen trade within and across GCC countries.
\end{abstract}

Keywords: Freight Trains; Air Cargo; Kuwait International Airport; railroad; GCC; Gulf Cooperation Council; transportation.

\section{INTRODUCTION}

Transportation is one of the major forces for economic progress. According to Ebert's and W E Upjohn Institute, transportation "is essential in the operation of a market economy, much still needs to be understood about ways in which an efficient transportation system can improve the productivity of the economy." In this regard, it is the goal of any government and nation to see itself improving and moving towards economic progress. Expanding transportation segment paths through railroad line construction, establishing and extending freight trains is a major development and the move towards this is especially projected for freight trains on the air cargo in Kuwait International Airport. The realization is made possible as Kuwait became a member of the Gulf Cooperation Council (GCC) and the Organization of Petroleum Exporting Countries which reflectively see economic potential for the country. The surplus in budget funds, reflects a strong financial position for the government, and thus opens the opportunity to push through with development efforts despite the current oil price dilemma.An estimated value of "USD 592 Bn." (Ebert's and W E Upjohn Institute).

Strategically located between the Kingdom of Saudi Arabia and Iraq, while facing Iran across the Gulf, Kuwait further projects business interest and access to various target markets in Asia, Turkey and in Europe. Compared to other GCC member countries, Kuwait currently has zero train networks. There is a relative potential for cargo to become an important contributor to the country that an imperative action is necessary to bridge locations and heighten the economic interest within. With the proposed Cargo City, KIA will cater and address the country's expanding logistical needs.Hence, this paper examines how establishing freight transportation (on the proposed Cargo City) will influence the air cargo in Kuwait International Airport.

\section{DISCUSSION}

\subsection{Kuwait International Airport}

Airport operations at Kuwait International Airport (KIA) has come a long way since it began in 1961 - the year when the state of Kuwait gained independence. The following year, the Kuwait government fully acquired ownership of the Kuwait Airways Company (KAC). Located 16 kilometers south of Kuwait City, the airport terminal building opened in 1980. It was complemented by a cargo terminal installed at its north-west side. Unfortunately, the airport facility was devastated during the Iraqi invasion of Kuwait in the early 1990s. The operations were later fully restored in December 1991. The Kuwait government poured in US\$60 million to modernize the airport in two phases. This expansion took place from 1999 to 2003. The airport started being managed by the Directorate General of Civil Aviation (DGCA) (History). Additional four new gates further expanded the capacity of the airport by $40 \%$. "The Kuwait International Airport has doubled its passenger traffic over the last 8 years, handling an increase from less than 5 million to 9 million passengers between 2004 and 2012, and with 12 million forecast by 2020" ("Airport Expansion Project Management"). The main catalyst for traffic growth in the airport was the adoption of the "open skies" policy. "Introduced in 
2006, it aims to liberalize the bilateral arrangements governing air traffic operations with other countries." (Kuwait). In 2013, KIA already hosted to 67 different airlines. "The Open Skies policy was in accordance to the vision of $\mathrm{HH}$ the Amir Sheikh Sabah Al-Ahmad Al-Jaber Al-Sabah, who sought to develop Kuwait into a commercial and business hub for the region is finally taking shape." ("Transport \& Logistics | Review: Transport").

\subsection{The Present Cargo Terminal}

Currently, KAC partially operates the enhanced air cargo services at KIA. The rest of the cargo and airport services like ramp, passenger, engineering, travel support, lounge, training center and security are operated by the National Aviation Services (NAS). NAS is a privately-run company. The existing cargo terminal is shown at the far upper left side of the picture below:

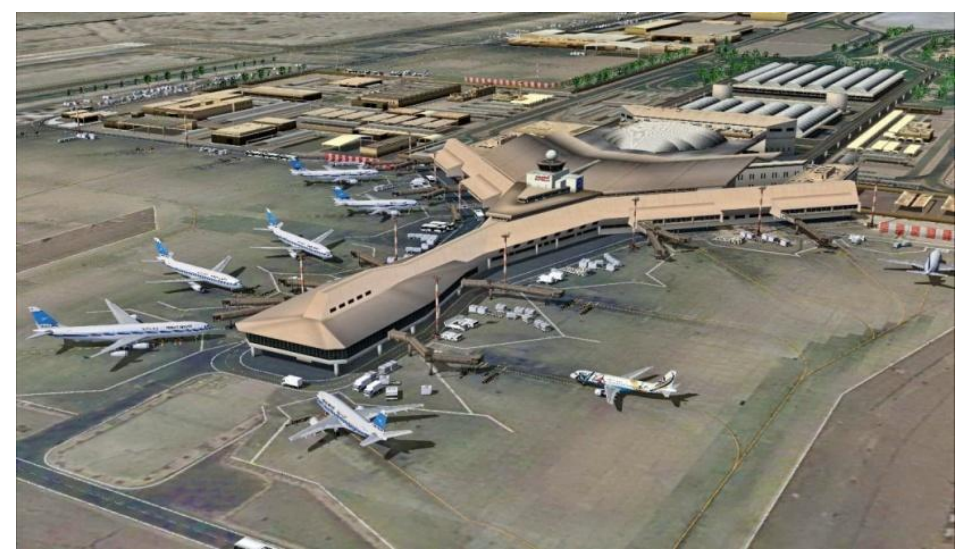

Image 1: KIA Existing Cargo Terminal (Ananda)

There was marked increase in the operations at the "8,000 cubic-meter" ("Cargo") KIA cargo complex after the installation of new facilities. The facilities cater to the various needs of the freight industry. One of the new facilities funded by more than "US\$3.1 million investment" ("Cargo") is the new consolidation facility which not only raised by " $10 \%$ the 126,000 tons of cargo" handled annually ("Cargo"), but also has improved efficiency of local forwarders in handling wider range of consignment. Such facility upgrade has maintained KIA as a principal freight focus in the Middle East.
The current cargo complex is divided into a 5,600 cubic-meter import warehouse and a 2,300 cubic-meter export facility. "With capacity for up to 600 tons of freight, the complex boasts a range of specialized facilities, in addition to general storage, enabling it to handle any kind of consignment" ("Cargo"). "The cargo terminal warehouses also have facilities for certain cargo types, including fridges, freezers, a strong room, racks, a radioactive material room, a special area for explosive cargo and a separate area for perishable cargo" (Koopmann).

\begin{tabular}{|c|c|c|}
\hline \multicolumn{3}{|c|}{ Current stock of Warehousing in Kuwait at sea ports and airport } \\
\hline Shuwaikh port & $\begin{array}{l}\text { Within the port } \\
\text { Warehouses: } \\
\text { Covered sheds: } \\
\text { Open storage area: } \\
\text { Outside the port area } \\
\text { Warehouses: } \\
\text { Covered sheds: } \\
\text { Open storage area: }\end{array}$ & $\begin{array}{r}70,000 \text { sq. m } \\
15,000 \text { sq. m } \\
500,000 \text { sq. } m\end{array}$ \\
\hline Shuaiba port & Warehouses: & 14,500 sq. m \\
\hline Doha port & Warehouses: & 8,110 sq. m \\
\hline $\begin{array}{l}\text { Kuwait International } \\
\text { Airport }\end{array}$ & $\begin{array}{l}\text { Import warehouse: } \\
\text { Export warehouse: }\end{array}$ & $\begin{array}{l}5,600 \text { sq. } m \\
2,300 \text { sq. m }\end{array}$ \\
\hline
\end{tabular}

Figure 2: Kuwait's Present Stock Warehousing at Seaports and Airport (Kuwait: A Guide for Investment Opportunities in Kuwait) 
Kuwait International Airport is the common hub for national carriers Kuwait Airways and low-cost airline Jazeera Airways. More airlines are taking advantage of the "open skies" policy in KIA. Moreover, the airport site is shared with the Al Mubarak Air Base, housing the Kuwait Air Force headquarters. Evidently, with the increasing bulk of air traffic, there is a need to expand the KIA to support the demand of airline passengers and cargo passing through it.

\subsection{The New KIA Terminal and the Proposed Cargo City \\ In response to these demands, in 2016, the} Kuwait government awarded the construction of a new passenger terminal to Turkish firm, Limak. This new terminal will cost US $\$ 4.3$ billion to build and it will also connect to the existing terminal through a tunnel. Once completed in the early 2020 s, KIA could then double its capacity to 25 million passengers per year. The proposed expansion of the terminal designed is shown in the figure below:

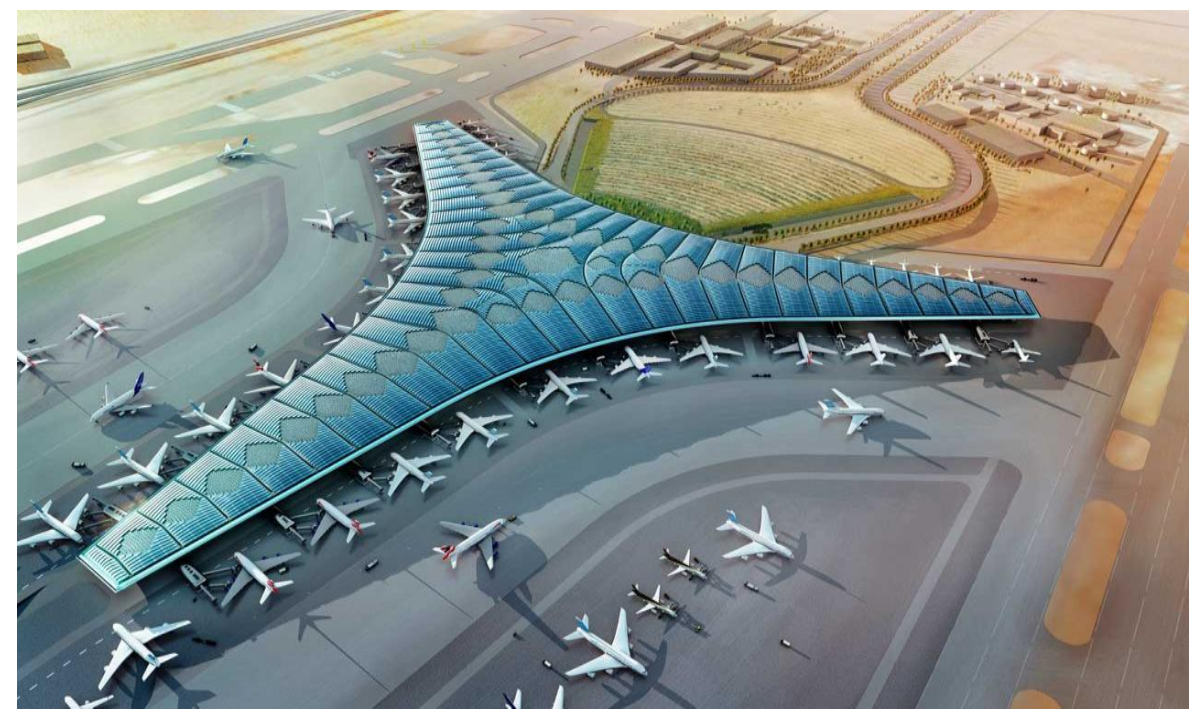

Figure 3: Proposed New KIA Terminal (Kuwait International Airport | Foster + Partners)

KIA's target capacity will be 50 million passengers and 6 million tons of cargo. Doing so will allow "the enhancements to further cement KIA's position as a regional hub and a world-class gateway, taking the airport's success story to a new level." ("KIA"). Additionally, the design takes into consideration the bulk of cargo that will be coming in. A Cargo City, shown at the upper right corner of the image below, will be another major element in the airport expansion.

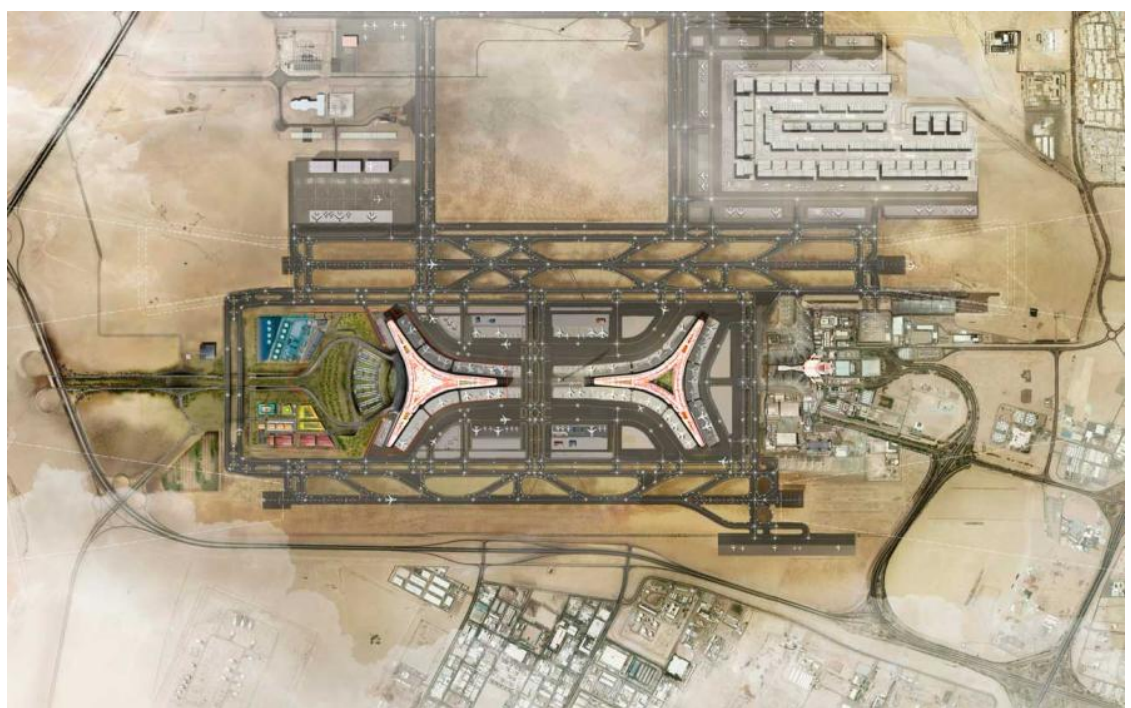

Figure 4: The Proposed New Terminals with the "Cargo City" at the upper right corner (Kuwait International Airport | Foster + Partners) 
Included in the latest terminal expansion proposal is the Cargo City within the KIA compound. "In addition to passenger-focused amenities, the airport will also include the large airfreight handling Kuwait Cargo City, which will cover 3 square-km and be the largest of its kind in the Middle East." (Capacity Upgrade: Kuwait Transport)."The two million square-meter cargo facility is planned to handle up to 70 A380 freighters and is planned to have an annual capacity of $6 \mathrm{mt}$ of cargo." ("Kuwait International Airport"). The building of the Cargo City expresses the intention to integrate a construction of the a railway to meet with the GCC National Railway which is the medium in which cargoes will be transported with.

Accordingly, the Kuwait government is encouraging private cargo companies to setup their operations in the Cargo City and consequently assist in providing employment. Aside from competitive rental fee or royalty, the main carrot stick will be the online Customs Automation
System. Airline cargo manifests will be electronically sent to Kuwait Customs upon departure of the aircraft. "Consignments are then precleared while the plane is in flight, helping to speed up release procedures after landing." ("Cargo"). A projection to the effects of expanding the KIA and creating the Cargo City shows that while nominal exports in 2014 show that from US $\$ 115 \mathrm{Bn}$, the sudden decrease to US\$ $74 \mathrm{Bn}$. is projected to rise again, even though 2019 is only seen to attain a foreseen value of US\$ $86 \mathrm{Bn}$. Compared to exports however, the projected figures show steady increase, such that from US\$ $50 \mathrm{Bn}$. in 2014, exports are seen to rise to US\$ 62 Bn. by 2019. Cargo City will correspondingly respond to meet the growth demands for the goods in the international air freight for which the project is designed for. With an increase in cargo transactions, the demand for warehousing and storage will increase as well. The data showing a detailed chart of both the import and export trend are shown in the figure below:

\section{Kuwait's import and exports, 2014-2019}

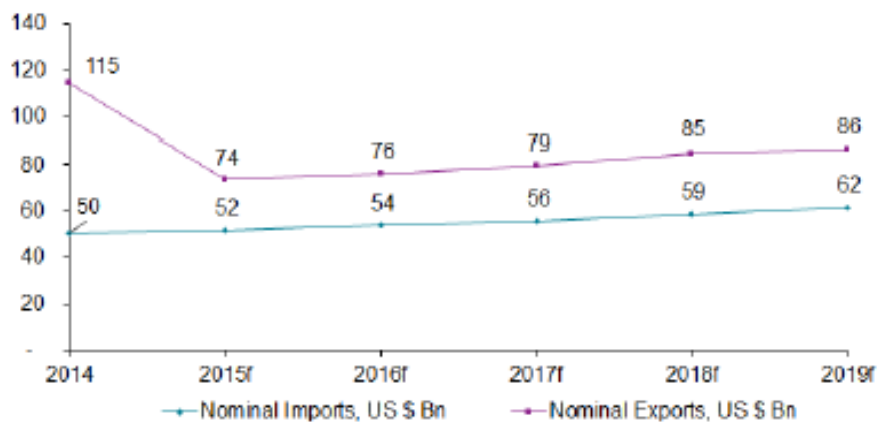

\section{NOMINAL IMPORTS, US \$Bn NOMINAL EXPORTS, US \$Bn}

Figure 5: Kuwait's Present and Future Trade (Kuwait: A Guide for Investment Opportunities in Kuwait)

Alternatively, as investments in Kuwait for imports and exports reflect a progressive trend, there will also be an impact to airfreight throughput. There are three points to consider in this aspect. First, a recognizable "domestic demand for freight logistics" (Kuwait: A Guide for Investment Opportunities in Kuwait) driven by the growth in agriculture, ores and metals advantageously found in Kuwait means that there is a renewed interest in the industrial business. Secondly, with the Mubarak Al Kabir port and other ports being developed, Kuwait's strategic location is seen to be an opportunity to further explore other export opportunities.

In connection to this, data shows that since 2014 , there is an increase in the number of tons for the international air freight throughput. By 2019, 210,000 tons are forecasted to enter KIA. Consequently, this justifies the increase in the demand for storage facilities for imports and exports. 


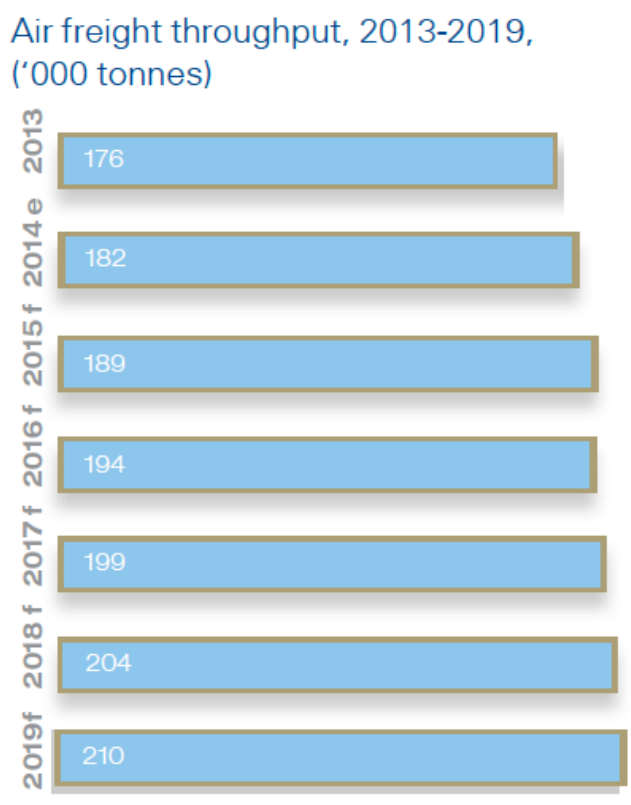

Figure 6: Kuwait's Present and Future Air Freight Throughput (Kuwait: A Guide for Investment Opportunities in Kuwait)

In comparison to the air freight throughput, the maritime freight throughput also reflects a progressive increase by 2019, emphasizing on million tons that go through the port annually. The ports of Shuaiba and Shuwaikh both relatively reveal increasing shipment and cargo transacting in the ports. Furthermore, "The planned Mubarak Al Kabir Port will add a capacity of additional $2.5 \mathrm{Mn}$ TEUs and facilitate access to regional markets" (Kuwait: A Guide for Investment Opportunities in Kuwait). This collectively sets the importance of establishing cargo trains that will not only connect airfreight cargo but connect maritime freight cargo as well.

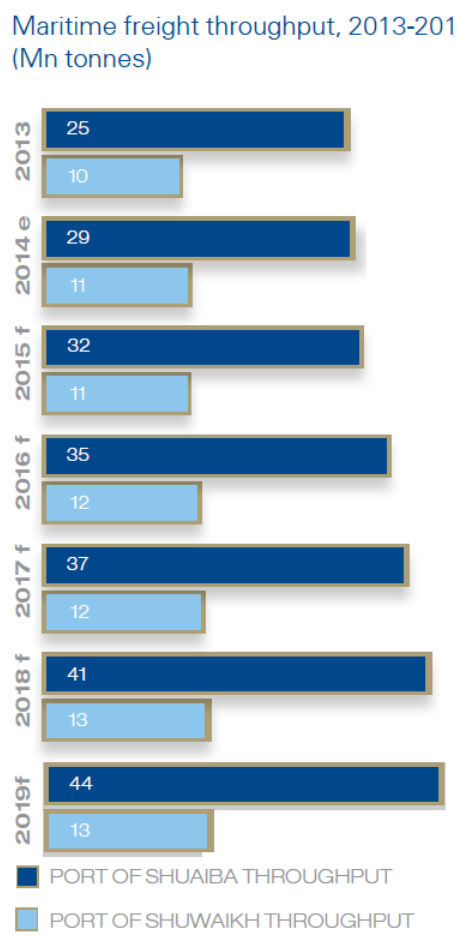

Figure 7 : Kuwait's Present and Future Maritime Freight (Kuwait: A Guide for Investment Opportunities in Kuwait) 


\subsection{The Need to Establish Freight Trains in Kuwait International Airport}

GCC member countries are connected together by land and logically, as geography dictates, land transport is the best option to transport cargo and passengers from one location to the other. Evidently, business and trade would have to rely on road transportation as air and marine transport is more expensive. Moreover, the expenses and the time consumed in air and marine transport with transit schedules can affect and slow down the trade process. Furthermore, some cargoes will have transportation limitations and would necessarily and ideally have to be transported through land rather than through air with commodities such as chemicals and materials used for construction. The figures below show that an estimate of 2.5 million metric tons of materials used for construction, agriculture, and chemicals pass through key points throughout the GCC countries yearly. Essentially, petrochemicals are the main economic drivers for most of the GCC member countries. With the petrochemical capacity continuously increasing, it reasonably increases the demand and need for transportation and storage requirements. It also opens up avenues to explore other commodities in trade.

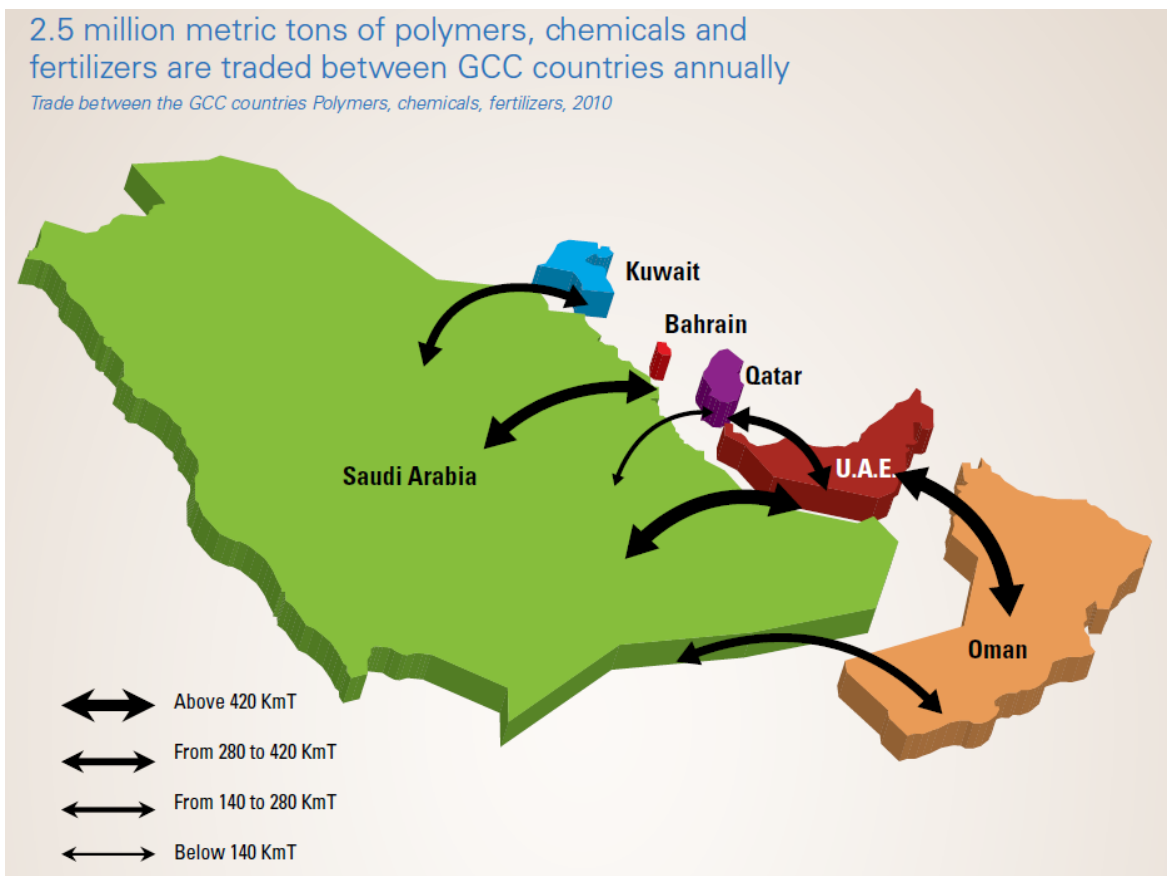

Figure 8: GCC Countries Trade Petrochemical Products Which Can Be Transported By Freight Trains (Gulf Rail Connection: Realizing GCC Unity)

With the prospective projections in increases, Kuwait has yet to complete construction of the air cargo freight transportation. It can be observed that even if Kuwait sustains itself economically even with the oil price situation, the fact is that there is an urgent need to connect in to the existing railroad system of other GCC countries. Obviously, the lack of railroad system will lead the country to lose probable revenues and opportunities. As other GCC member countries realize that a dynamic change reflecting on the business and economic development of the neighboring countries would mean adapting to the trend, Kuwait can use this opportunity to progressively create avenues and position itself like other GCC countries. Substantial information already points toward changing perspectives while weighing in on the impact and influences air cargo freight trains will have as it is built in the key positions identified.

Looking at the existing rail road system, it can be seen that the KIA is strategically situated inbetween Kuwait City, industrial zones and its seaports, in the north, and the GCC Railway Network in the south. The existing railway line is highlighted in red, as the figure shows below. Evidently, the railway line location passes through commercial and important places starting from the airport terminal. With the existing lines interconnecting to other paths, it situates Kuwait as a noticeable route for business. Ultimately, a railway line for both passengers and cargo is highly feasible to interconnect other important facilities. 


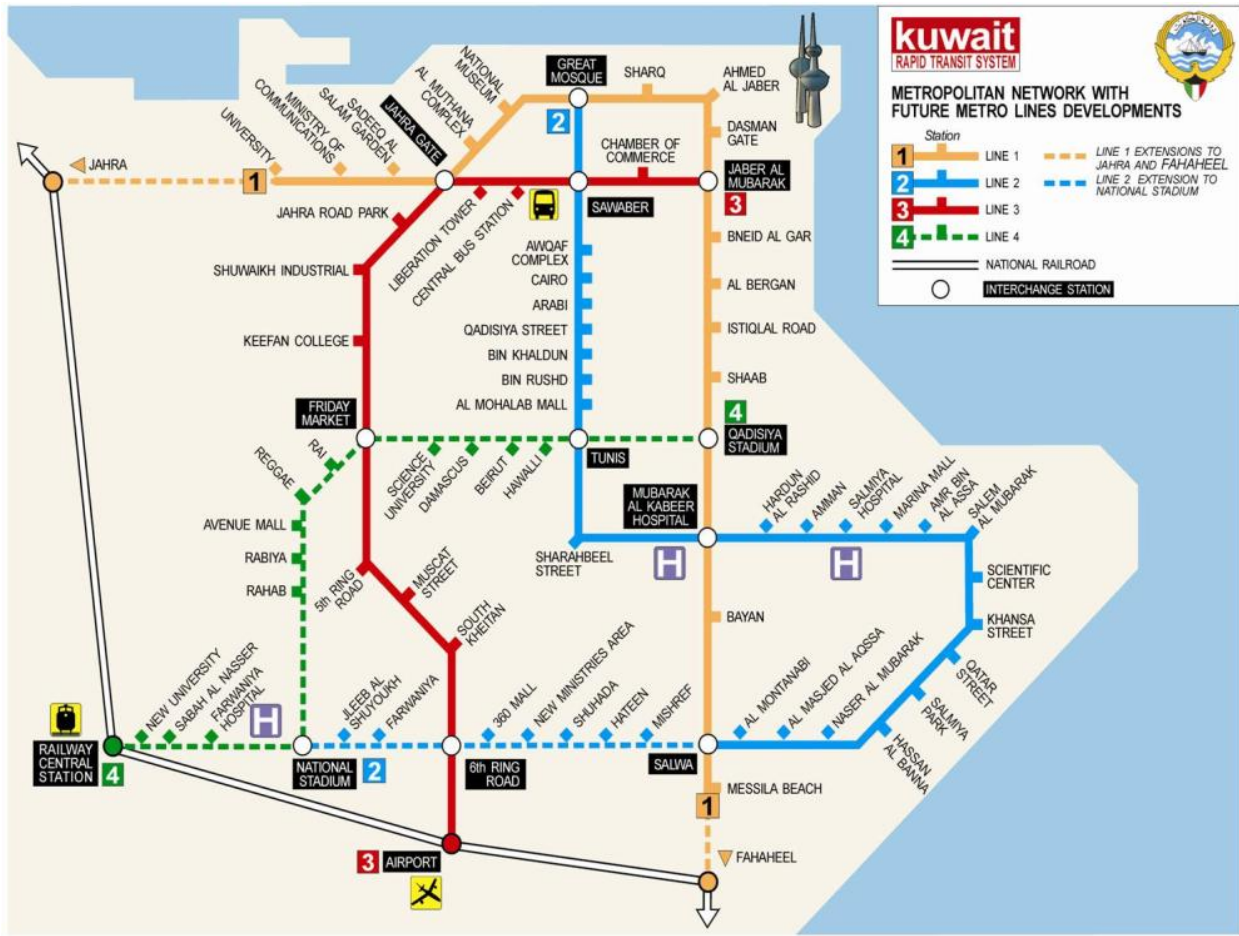

Figure 9: Kuwait Metro Map (Kuwait City Metro Map)

\subsection{The GCC Railway Network}

The idea is to create a GCC railway network that will take over the freight volume and remove the congestion it will create for air freight and maritime freight as well. Kuwait City is an integral part of this project as it will be linked to other GCC countries, "traversing along the Gulf, to Muscat in the Sultanate of Oman, serving the Kingdom of Saudi Arabia, the Kingdom of Bahrain, the State of Qatar and the United Arab
Emirates" (Gulf Rail Connection: Realizing GCC Unity). Crucial to this plan is the concept that the GCC railways will connect major commercial and economic locations, thereby additionally creating a continuous railway line accessible to passengers and cargoes for the GCC region and the Middle East. The figure below illustrates exactly how the planned railway network will provide strategic transport access to vital locations.

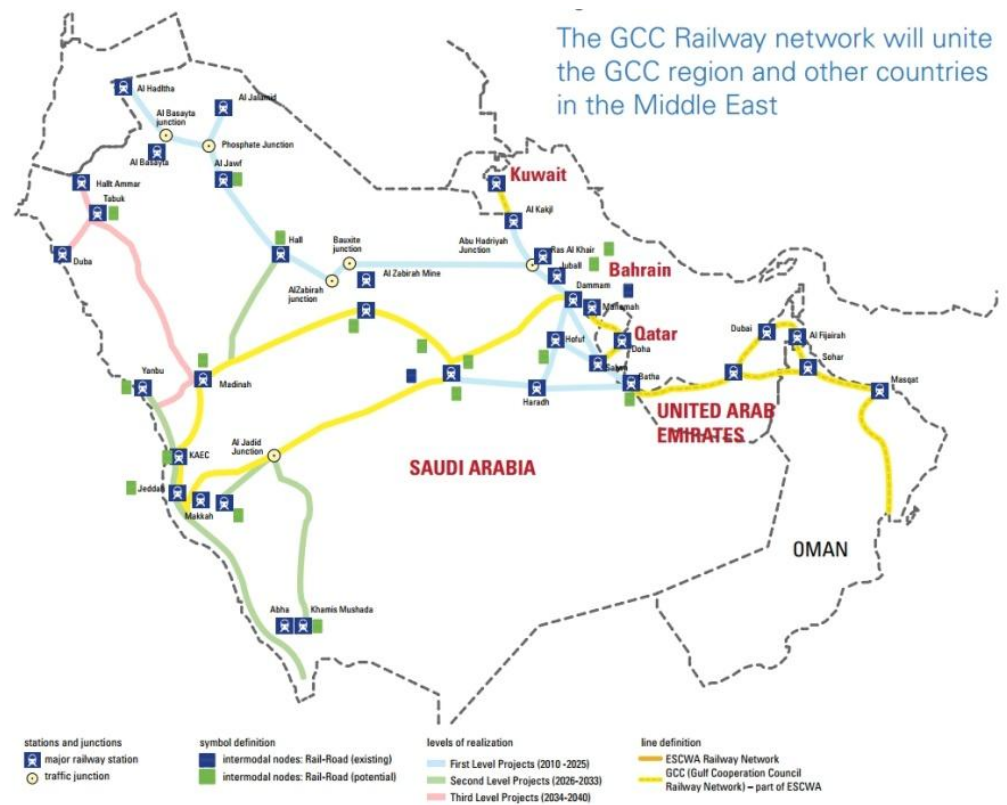

Figure 10: GCC Railway Network (Gulf Rail Connection: Realizing GCC Unity) 
Historically, the trace or tracks of the proposed GCC railway network was once an important means of transporting "pilgrims from Damascus in Syria to the holy city of Madinah in Saudi Arabia, through the Hejaz region of Arabia" (Frost \& Sullivan). Transporting passengers through the desert was halted during the World War I, which consequently destroyed the railway line, causing it to be closed. Rebuilding the railway network proved even more challenging despite the efforts from neighboring countries as points of view, most especially political differences underscore the idea of reviving the network. Thus, the idea of some GCC countries like Kuwait has not given priority to building rail networks, while other Middle East member countries have advanced to developing their rail network. As Frost (et.al.) finds in the study, "none of the GCC nations embraced railways as a prominent mode of transport, either for passenger or cargo movement."

\subsection{Influence of freight trains on air cargo at KIA}

As established earlier, the need to link and establish a railway network with other GCC member countries' railroad networks will create a business advantage for Kuwait. The Business Year reports that, "Kuwait's national rail project will facilitate growth in the volume of exports and imports, and it is expected to be an added support towards increasing inward investment" ("One Rail to Link Them All"). The proposed terminal collectively aims to cater to the projected cargo transport needs and requirements that the latest design of the new terminal ensures the "transformation of KIA into a major multi-modal transport hub, with road and rail connections as well as an expanded cargo facility." (Capacity Upgrade: Kuwait Transport). There are plans to connect the new airport terminal to Kuwait City, the industrial area and the northern seaports via a metro train line. Furthermore, there is a proposal to link the metro with the GCC railway network. "The first phase would link the rail freight depotwhich is to be connected with the GCC rail network-with Kuwait International Airport and into Kuwait City and construction is expected to commence in 2020." ("Transport \& Logistics | Review: Transport"). The project will formally integrate Kuwait to the GCC railway network, and will be crucial to boost regional trade and promote employment. "It is one of the major infrastructure projects in Kuwait's Vision 2035..." (“One Rail to Link Them All"). The total cost of the two train projects is about US\$17 billion. "Major projects include the national railroad, with a projected cost of $\$ 10$ billion and a completion date of 2018, the Kuwait City metro network, to be completed in
2019 at \$7 billion...” (“Transport \& Logistics Review: Transport")."Kuwait has become one of the most important business centres in the Middle East. It is undergoing a population growth rate of over $3.5 \%$ annually, one of the fastest in the world."(“AirportExpansion Project Management"). It is estimated that private vehicles carry 99 percent of the passengers and goods. The future scenario is that the current road network will be overwhelmed within 10 years if no transport alternative is provided. Freight trains can influence air cargo in KIA in many ways. The link with GCC member countries will provide radical improvements and changes for Kuwait. Fundamentally, "an ambitious GCC rail network linking Kuwait with Muscat could be up and running by 2017 " (Gale). A major influence of freight trains is that one freight train is equivalent to 50 trucks, which means overall efficiency and positive direction to improvement as using freight trains consumes " $60-80$ per cent less energy per kilometer than road transport" (Frost \& Sullivan), and given that freight trains are faster than trucks. This further stresses on "decreasing current delays experienced at borders for both freight and passengers" (Gulf Rail Connection: Realizing GCC Unity).

In environmental terms, freight trains give out as much as "80 per cent lesser CO2 emissions" (Frost \& Sullivan) than land transportation. Additionally, since the number of trucks would be reduced, traffic would improve and "protect infrastructures impacted by excessive use of roads with overweight loads and contributes to minimizing road related accidents" (Gulf Rail Connection: Realizing GCC Unity). Because of the dimensions of a freight train, it can transport almost any type of cargo.

The freight trains are secured alternative to shipping when there are intermittent (political) threats on the sea lanes, particularly in the Strait of Hormuz. The railway may be another viable option during rare case of "no-fly zone" declaration."The addition of on-board inspectors, supported by preclearance immigration procedures based at the point of journey origin will make railway transport more efficient and competitive; decreasing current delays experienced at borders for both freight and passengers." (Gulf Rail Connection: Realizing GCC Unity).There will be increased development around where train stations are constructed. Residential and commercial establishment will gradually partake in the business opportunities that follows. "They (Railway stations) also allow people more flexibility as to where they live and where they work, delivering net gains in higher paid jobs and leveraging lower housing, education and employment costs." ("GCC Rail Infrastructure Projects: The Challenges and the Benefits"). 
Imagine the employment growth in and around the expanded KIA terminal and Cargo City. Facilities management of such massive infrastructures has potential business opportunities after construction. This could run to hundreds of millions of dollars on an annual basis.

It is estimated that rail-road transport of goods is about $30 \%$ cheaper than by road (Frost \& Sullivan). However, Lowe and Altrairiargue that "The rail transportation of bulk solids and liquids as well as containerised cargo will be cheaper than road provided that the journey is over $500 \mathrm{~km}$." In the future, the GCC train network could extend to Europe via Iraq and through Turkey, as well as simulate the "Silk Road" (Gulf Rail Connection: Realizing GCC Unity) all the way to China. Essentially, GCC member countries all benefit with the railroad expansion. It is anticipated that a positive GDP foresighted at 5 percent annually will be a huge influencing factor considering that population is forecasted to increase at $50 \%$ annually until 2024.

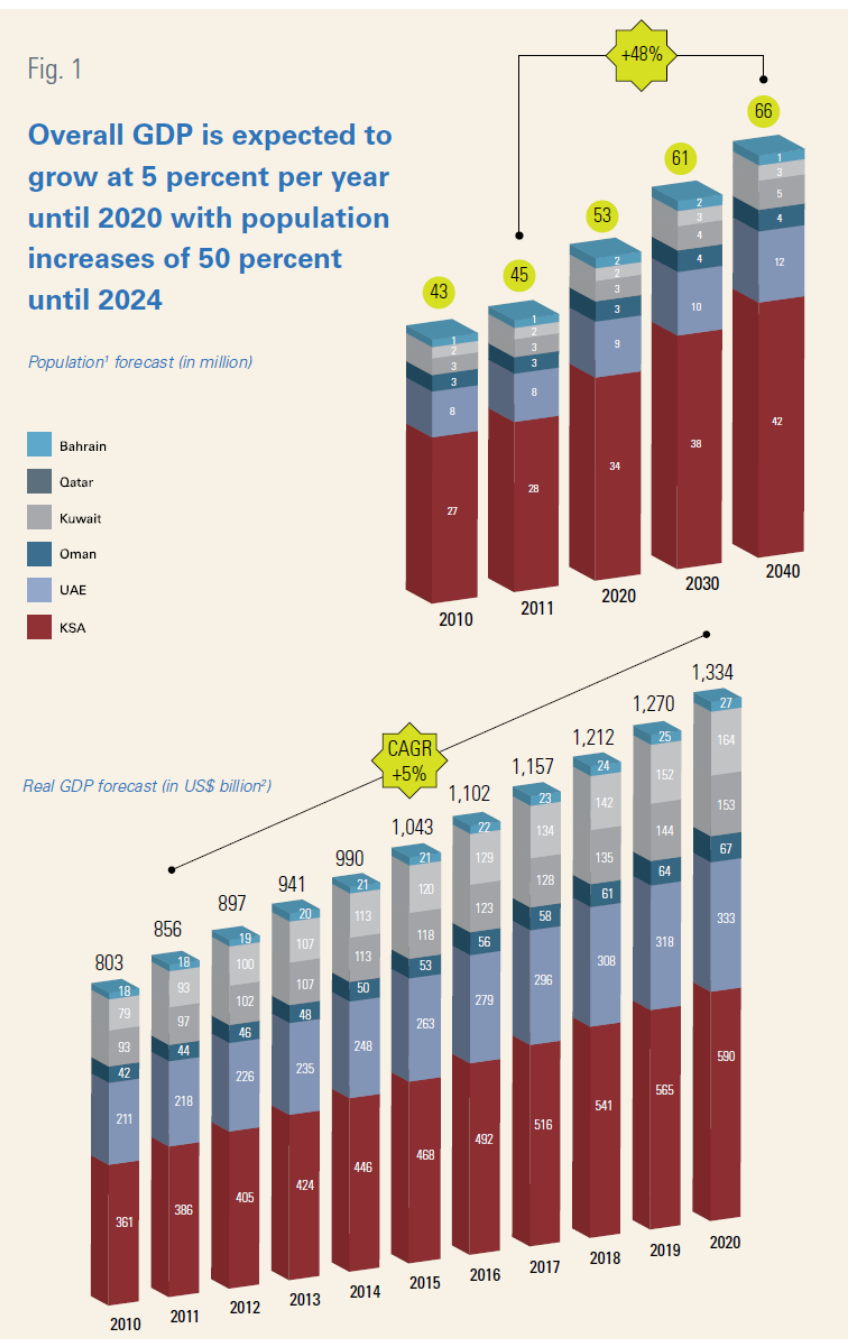

Figure 11: GDP Expectations of GCC-member States (Gulf Rail Connection: Realizing GCC Unity)

\section{METHODOLOGY}

The methodology of this research is historical in the essential part, and descriptive in the field part, my tool is documentation and using the interview with key person in the field.

\section{CONCLUSION}

The paper primarily sought to discover and examine the influences of establishing freight trains on the Air Cargo in Kuwait International
Airport. Implications to establishing freight trains are emphasized by discussing the situation of the KIA. Currently, the airport operates with two major airlines, the Al Jazeera Airways and Kuwait Airways.Recent developments have seen that there is an increase in the cargo requirements and that in order for airfreight management to cater to the increasing demand, expansion of the airport and the creation of Cargo City, which will become the destination center for cargo and connectedly 
become the main site for warehousing and storage.This impact and influences for the establishment of the Cargo City is commanded by the drivers of economic growth and development. More specifically, projected benefits corresponding to advancing the export and import practices and revenue returns makes Kuwait and important location to link with the GCC railway system.

\section{RECOMMENDATION}

Expansion of Kuwait international airport is essential to develop freight transit on the Air cargo, and post economic progress.

\section{REFERENCES}

[1]. “Airport Expansion Project Management." Ineco, Https://Www.Ineco. Com/Webineco/ En/Country/ Spain/ Project-Management-Kuwait-Airport. Accessed 18 Jan. 2017.

[2]. Ananda, Nicola. "Scenery Armi Kuwait International Airport (Okbk) \#Fsx." Fs Nusantara The Center For Addons Flight Simulator, 2014 , Http://Fsnusantara.Blogspot.Com/2015/07 /Download-Scenery-Armi-Kuwait.Html. Accessed 18 Jan. 2017.

[3]. Capacity Upgrade: Kuwait Transport. Oxford Business Group, 22 Aug. 2015, Https://

Www.Oxfordbusinessgroup.Com/Profile/ Capacity-Upgrade. Accessed 19 Jan. 2017.

[4]. "Cargo." Direactorate General Of Civil Aviation,

Https://Www.Dgca.Gov.Kw/En/Civil-

Aviation/ Airport- Services/AviationServices/Cargo. Accessed 16 Jan. 2017.

[5]. Eberts, Randall, And W E Upjohn Institute. Understanding The Impact Of Transportation On Economic Development. Committee On Transportation And Economic Development.

[6]. Frost \& Sullivan. Strategic Insight On The Gcc Rail Sector. 2011.

[7]. Gale, Ivan. Kuwait-Oman Train Could Run By 2017. 14 Oct. 2009, Http://Www. Thenational.Ae/ News/UaeNews/Transport/Kuwait-Oman-TrainCould-Run-By-2017. Accessed 19 Jan. 2017.

[8]. "Gcc Rail Infrastructure Projects: The Challenges And The Benefits." Lexology, 2006,

Http://Www.Lexology.Com/Library/Detai
Studies and statistics reveal supporting claims on the idea from the year 2014, as figures show a continuing rise in commodity demands as well as trade for these commodities. Overall, the air freight cargo will move transport will pave the way to an expansion to other neighboring countries, including an exploration to the "Silk Road".

1.Aspx?G=F41bb543-Bd9c-43af-9e299d726bd2bcd1. Accessed 19 Jan. 2017.

[9]. Gulf Rail Connection: Realizing Gcc Unity. Gulf Petrochemicals And Chemical Association, 2012.

[10]. History. Http://Www.KuwaitAirport.Com.Kw/Dgca/History_E.Htm. Accessed 18 Jan. 2017.

[11]. "Kia." Directorate General Of Civil Aviation,

Https://Www.Dgca.Gov.Kw/En/CivilAviation/Airport-Terminals/Kia. Accessed 18 Jan. 2017.

[12]. Koopmann, Karla. Kuwait International Airport - Logistics Capacity Assessment. 2012,

Http://Dlca.Logcluster.Org/Display/Public /Dlca/2.2.1+Kuwait+International+Airport ;Jsessionid=Fc2a0040f861ddf324a8a45b5 86fe6b4\#Id-

2.2.1kuwaitinternationalairport-

Companiesavailable. Accessed 18 Jan. 2017.

[13]. Kuwait. Icao International Civil Aviation Organization.

[14]. Kuwait City Metro Map. Http://3m3cna178rlp1rclw43v482p.Wpen gine.Netdna-Cdn.Com/Images/ 2014/07/ Kuwait-City-Metro-Map.Jpg. Accessed 19 Jan. 2017.

[15]. "Kuwait International Airport." AirportTechnology.Com, Airport Technology, Http://Www.Airport-

Technology.Com/Projects/KuwaitInternational/. Accessed 18 Jan. 2017.

[16]. Kuwait International Airport | Foster + Partners. 2011, Http://Www. Fosterandpartners. Com/Projects/ KuwaitInternational-Airport/\#. Accessed 18 Jan. 2017.

[17]. Kuwait Rapid Transit System. Http://3m3cna178rlp1rclw43v482p.Wpen gine.Netdna-Cdn.Com Images/ 2014/07/ Kuwait-City-Metro-Map.Jpg. Accessed 18 Jan. 2017.

[18]. Kuwait: A Guide For Investment Opportunities In Kuwait. Kuwait Direct Investment Promotion Authority, 2015. 
[19]. Lowe, John G, And Ibrahim Saud Altrairi. The Gulf Cooperation Council Railway. No. 2, 2013, Pp. 1147-

1157,Http://Www.Arcom.Ac.Uk/Docs/Proceedings/Ar2013-1147-

1157_Lowe_Altrairi.Pdf. Accessed 19 Jan. 2017.

[20]. "One Rail To Link Them All." The Business Year, 2016, Https:/ Www.Thebusinessyear.Com/Kuwait2016/One-Rail-To-Link-Them-All/Focus. Accessed 18 Jan. 2017.

[21]. "Transport \& Logistics | Review: Transport." The Business Year, 2016, Https:/Www. Thebusinessyear. Com/ Kuwait-2016/Only-Connect/Review. Accessed 17 Jan. 2017. 